\title{
INEQUALITIES INVOLVING NORM AND ESSENTIAL NORM OF WEIGHTED COMPOSITION OPERATORS
}

\section{Ajay K. Sharma, Ambika Bhat, Renu Chugh and Elina Subhadarsini}

Abstract. We characterize the boundedness and compactness of the weighted composition operator acting from the weighted Bergman space $\mathscr{A}^{p}(\sigma)$ to the Zygmund-type space $\mathscr{Z}_{v}$, where $\sigma$ is an admissible weight and $v$ is a normal weight. Some upper and lower bounds for the norm and essential norm of the operator are also given.

Mathematics subject classification (2010): Primary 47B33, 46E10; Secondary 30D55.

Keywords and phrases: Weighted composition operator, admissible weight, normal weight, weighted Bergman space, Zygmund-type space.

\section{REFERENCES}

[1] C. C. COWEn AND B. D. MACClueR, Composition operators on spaces of analytic functions, CRC press, Boca Raton, New York, 1995.

[2] K. Kellay AND P. LefEVRE, Compact composition operators on weighted Hilbert spaces of analytic functions, J. Math. Anal. Appl. 386 (2012), 718-727.

[3] Z. J. JiAng, On Stević-Sharma operator from the Zygmund space to the Bloch-Orlicz space, Adv. Difference Equ., Vol. 2015, Article ID 228, (2015), 12 pages.

[4] H. Li AND Z. GUO, On a product-type operator from Zygmund-type spaces to Bloch-Orlicz spaces, J. Inequal. Appl., Vol. 2015, Article no. 132, (2015), 18 pages.

[5] S. Li And S. STević, Volterra-type operators on Zygmund spaces, J. Inequal. Appl., Vol. 2007, Article ID 32124, (2007), 10 pages.

[6] S. Li AND S. S TEVIĆ, Weighted composition operators from Bergman-type spaces into Bloch spaces, Proc. Indian Acad. Sci. Math. Sci. 117 (2007), 371-385.

[7] S. Li AND S. STEVIĆ, Generalized composition operators on Zygmund spaces and Bloch type spaces, J. Math. Anal. Appl. 338 (2008), 1282-1295.

[8] S. Li AND S. STEVić, Products of Volterra type operator and composition operator from $H^{\infty}$ and Bloch spaces to the Zygmund space, J. Math. Anal. Appl. 345 (2008), 40-52.

[9] S. Li AND S. STEVIĆ, Weighted composition operators from Zygmund spaces into Bloch spaces, Appl. Math. Comput. 206 (2008), 825-831.

[10] S. Li AND S. STEVIĆ, Integral-type operators from Bloch-type spaces to Zygmund-type spaces, Appl. Math. Comput. 215 (2009), 464-473.

[11] S. Li AND S. SteVić, On an integral-type operator from $\omega$-Bloch spaces to $\mu$-Zygmund spaces, Appl. Math. Comput. 215 (2010), 4385-4391.

[12] S. Li AND S. STEVIĆ, Products of composition and differentiation operators from Zygmund spaces to Bloch spaces and Bers spaces, Appl. Math. Comput. 217 (2010), 3144-3154.

[13] A. K. Sharma AND S. UEKI, Composition operators between weighted Bergman spaces with admissible Bekolle weights, Banach J. Math. Anal. 8 (2014), 64-88.

[14] S. STEVIĆ, Essential norms of weighted composition operators from the $\alpha$-Bloch space to a weightedtype space on the unit ball, Abstr. Appl. Anal. 2008, Art. ID 279691, 11 pp.

[15] S. STEvić, Composition operators from the Hardy space to the Zygmund-type space on the upper half-plane, Abstr. Appl. Anal., Vol. 2009, Article ID 161528, (2009), 8 pages.

[16] S. STEVIĆ, Norm and essential norm of composition followed by differentiation from $\alpha$-Bloch spaces to $H^{\infty}$, Appl. Math. Comput. 207 (2009), 225-229. 
[17] S. STEVIĆ, On an integral operator from the Zygmund space to the Bloch-type space on the unit ball, Glasg. J. Math. 51 (2009), 275-287.

[18] S. STEVIĆ, Products of integral-type operators and composition operators from the mixed norm space to Bloch-type spaces, Siberian Math. J. 50 (4) (2009), 726-736.

[19] S. STEVIĆ, Weighted composition operators from weighted Bergman spaces to weighted-type spaces on the unit ball, Appl. Math. Comput. 212 (2009), 499-504.

[20] S. STEvić, Composition followed by differentiation from $H^{\infty}$ and the Bloch space to $n$th weightedtype spaces on the unit disk, Appl. Math. Comput. 216 (2010), 3450-3458.

[21] S. STEVIĆ, Composition operators from the weighted Bergman space to the nth weighted-type space on the upper half-plane, Appl. Math. Comput. 217 (2010), 3379-3384.

[22] S. STEVIĆ, Composition operators from the Hardy space to the nth weighted-type space on the unit disk and the half-plane, Appl. Math. Comput. 215 (2010), 3950-3955.

[23] S. STEvić, Composition operators from the Hardy space to Zygmund-type spaces on the upper halfplane and the unit disc, J. Comput. Anal. Appl. 12 (2010), 305-312.

[24] S. STEVIĆ, Weighted differentiation composition operators from the mixed-norm space to the nth weighted-type space on the unit disk, Abstr. Appl. Anal., 2010, Art. ID 246287, 15 pp.

[25] S. STEvić, Weighted differentiation composition operators from $H^{\infty}$ and Bloch spaces to nth weigthed-type spaces on the unit disk, Appl. Math. Comput. 216 (2010), 3634-3641.

[26] S. STEVIĆ, Weighted radial operator from the mixed-norm space to the nth weighted-type space on the unit ball, Appl. Math. Comput. 218 (2012), 9241-9247.

[27] S. Stević And A. K. Sharma, Composition operators from Bergman Privalov spaces to Zygmund spaces, Ann. Polon. Math. 105 (2012), no. 1, 77-86.

[28] S. Stević And A. K. Sharma, Weighted composition operators from weighted Bergman spaces with Békollé weights to Bloch-type spaces, J. Inequal. Appl. 2015, 2015:337, 14 pp.

[29] S. STEvić, A. K. Sharma, AND A. Bhat, Products of multiplication composition and differentiation operators on weighted Bergman spaces, Appl. Math. Comput. 217 (2011), 8115-8125.

[30] S. STEVIĆ, A. K. Sharma AND A. Bhat, Essential norm of products of composition multiplication and differentiation between weighted Bergman spaces, Appl. Math. Comput. 218 (2011), 2386-2397.

[31] S. STEVIĆ AND S. I. UEKI, On an integral-type operator acting between Bloch-type spaces on the unit ball, Abstr. Appl. Anal. 2010, Art. ID 214762, 14 pp.

[32] S. I. UEKI, On the Li-Stević integral type operators from weighted Bergman spaces into Zygmung spaces, Integr. Equ. Oper. Theory 74 (2012), 137-150.

[33] X. ZHU, Extended Cesáro operator from $H^{\infty}$ to Zygmund type spaces in the unit ball, J. Comput. Anal. Appl. 11 (2009), 356-363.

[34] X. ZHU, Integral-type operators from iterated logarithmic Bloch spaces to Zygmund-type spaces, Appl. Math. Comput. 215 (2009), 1170-1175. 